\title{
Relatório Anual de Gestão - 2010
}

\section{Artigos publicados}

Na Revista E\&G v. 10, n. 22, 23 e 24, foram publicados 18 Artigos, 01 Caso de Ensino, 01 Ensaio e 01 Entrevista de 52 autores.

\section{Autoria e conteúdo}

\section{Origem geográfica dos autores}

\begin{tabular}{lcc}
\hline \multicolumn{1}{c}{ Origem dos autores } & Quantidade & \% \\
\hline Portugal & 2 & 3,85 \\
Minas Gerais & 21 & 40,38 \\
Paraná & 2 & 3,85 \\
Rio de Janeiro & 1 & 1,92 \\
Rio Grande do Sul & 5 & 9,62 \\
Santa Catarina & 9 & 17,31 \\
São Paulo & 11 & 21,15 \\
Espírito Santo & 1 & 1,92 \\
Total & 52 & 100,00 \\
\hline
\end{tabular}

Origem institucional dos autores

\begin{tabular}{l|ccccc}
\hline \multicolumn{1}{c|}{ Edição } & PUC Minas & $\begin{array}{c}\text { Demais } \\
\text { instituições }\end{array}$ & $\begin{array}{c}\text { Total de } \\
\text { autores }\end{array}$ & $\begin{array}{c}\text { Quantidade } \\
\text { de artigos }\end{array}$ \\
\hline $\begin{array}{l}\text { v. 10 n. 22 quantidade } \\
\text { porcentagem }\end{array}$ & $25 \%$ & 15 & 17 & 7 \\
\hline v. 10 n. 23 quantidade & $25 \%$ & $34,09 \%$ & $32,69 \%$ & $33,33 \%$ \\
porcentagem & $50 \%$ & 13 & 17 & 7 \\
\hline v. 10 n. 24 quantidade & 2 & $29,54 \%$ & $32,69 \%$ & $33,33 \%$ \\
porcentagem & $25 \%$ & 16 & 18 & 7 \\
\hline Total & 8 & $36,36 \%$ & $34,61 \%$ & $33,33 \%$ \\
\hline
\end{tabular}

\section{Gestão editorial}

Em 30 de dezembro de 2010, a posição dos artigos conforme o processo de submissão, avaliação e publicação apresentou os seguintes resultados:

\begin{tabular}{lcc}
\hline \multicolumn{1}{c|}{ Situação dos trabalhos } & $\mathbf{N}^{\mathbf{0}}$ & $\mathbf{\%}$ \\
\hline Artigos submetidos à Revista E\&G & 34 & 32,6 \\
Artigos publicados após adaptações sugeridas pelos pareceristas ad hoc & 21 & 20,1 \\
Artigos aprovados pelos pareceristas ad hoc e aguardando publicação & 4 & 3,8 \\
Artigos em processo de análise pelos pareceristas ad hoc & 27 & 26,9 \\
Artigos não aceitos após avaliação dos pareceristas ad hoc & 4 & 3,8 \\
Artigos retirados de pauta & 14 & 13,4 \\
Total & 104 & 100 \\
\hline
\end{tabular}

Intervalo médio de recebimento e aprovação do artigo: 260 dias. 
4 Nominata de pareceristas ad hoc 2010

Prof. Dr. Bezamat de Souza Neto

Departamento de Ciências Administrativas e Contábeis da Universidade Federal de São João Del Rei

Prof. Caio Cesar Giannini Oliveira

Faculdade de Comunicação e Artes da Pontifícia Universidade Católica de Minas Gerais

Prof $^{\mathrm{a}}$. Dr ${ }^{\mathrm{a}}$. Denise de Castro Pereira

Instituto de Ciências Econômicas e Gerenciais da Pontifícia Universidade Católica de Minas Gerais

Prof $^{a}$. Dr ${ }^{a}$. Denize Grzybovski

Departamento de Ciências Econômicas, Administrativas e Contábeis da Universidade de Passo Fundo

Prof. Dr. Humberto Elias Garcia Lopes

Programa de Pós-Graduação em Administração da Pontifícia Universidade Católica de Minas Gerais

Prof $^{\mathrm{a}}$. Dra ${ }^{\mathrm{a}}$. Irene Raguenet Troccoli

Universidade Estácio de Sá

Prof. Dr. Jairo Laser Procianoy

Departamento de Ciências Administrativas da Universidade Federal do Rio Grande do Sul

Prof. Dr. José Arimatés de Oliveira

Departamento de Ciências Administrativas da Universidade Federal do Rio Grande do Norte

Prof $^{\mathrm{a}}$. Dra. Maria Ceci Misoczky

Departamento de Ciências Administrativas da Universidade Federal do Rio Grande do Sul

Prof $^{a}$. Dra. Maria Elisa Brandão Bernardes

Departamento de Ciências Administrativas da Fundação Dom Cabral

Prof $^{a}$. Dr ${ }^{a}$ Marta Araújo Tavares Ferreira

Programa de Pós-Graduação em Administração da Pontifícia Universidade Católica de Minas Gerais

Prof $^{a}$. Dra. Moema Miranda de Siqueira

Departamento de Ciências Administrativas da Universidade Federal de Minas Gerais 
Prof. Dr. Oscar Claudino Galli

Departamento de Ciências Administrativas da Universidade Federal do Rio Grande do Sul

Prof. Pedro Paulo Pettersen

Departamento de Ciências Econômicas da Pontifícia Universidade Católica de Minas Gerais

Prof. Rafael Kruter Flores

Departamento de Ciências Administrativas da Universidade Federal do Rio Grande do Sul

Prof. Dr. Ricardo Fonseca Rabelo

Departamento de Economia do Instituto de Ciências Econômicas e Gerenciais da Pontifícia Universidade Católica de Minas Gerais

Prof. Dr. Ricardo Luiz Pereira Bueno

Departamento de Administração da Universidade Federal Fluminense

Prof. Dr. Salomão Alencar Farias

Departamento de Ciências Administrativas da Universidade Ferderal de Pernambuco

Prof $^{\mathrm{a}}$. Dra. Simone Costa Nunes

Programa de Pós-graduação em Administração da Pontifícia Universidade Católica de Minas Gerais

Prof ${ }^{\mathrm{a}}$. Dra. Sueli Goulart

Departamento de Ciências Administrativas da Universidade Federal do Rio Grande do Sul

Prof $^{\mathrm{a}}$. Dra. Ursula Wetzel

Departamento Administração do Instituto Coppead de Administração da Universidade

Federal do Rio de Janeiro

Prof $^{\mathrm{a}}$. Dra. Vânia Maria Jorge Nassif

Departamento de Ciências Administrativas da Universidade Presbiteriana de Mackenzie de São Paulo

\section{5 Índice por autor - Publicações 2010}

ALMEIDA, Aulus Gelius Valadares de TAP Portugal: o Desafio de Ser Fênix v. 10 n. 23 p. $118-134$ maio/ago. 2010

ALMEIDA, Martinho Isnard Ribeiro de O Estado da arte em estratégia na Revista de Administração Contemporânea: um 
estudo bibliométrico

v. 10 n. 24 p. $28-47$ set./dez. 2010

ALTAF, Joyce Gonçalves

A importância da gestão profissional em uma Empresa Familiar - Joalharia Meridiano Ltda v. 10 n. 23 p. $40-58$ maio/ago. 2010

BAETA, Adelaide Maria Coelho

Gestão da Informação numa IES: estudo de caso aplicado à avaliação para autorização e reconhecimento de cursos de graduação

v. 10 n. 22 p. $67-87$ jan./abril 2010

BERTUCCI, Janete Lara de Oliveira

Alavancagem Financeira como Estratégia de Financiamento do Processo de Crescimento de Empresas Brasileiras de Capital Aberto no Período 1995-2002

v. 10 n. 23 p. 23-39 maio/ago. 2010

BERTUCCI, Luiz Alberto

Alavancagem Financeira como Estratégia de Financiamento do Processo de Crescimento de Empresas Brasileiras de Capital Aberto no Período 1995-2002

v. 10 n. 23 p. 23-39 maio/ago. 2010

BESSEGATO, Lupércio França

A alocação de recursos dos regimes próprios de previdência social tem sido eficiente?

v. 10 n. 24 p. $48-73$ set./dez. 2010

BEUREN, Ilse Maria

Métodos de preço de transferência interna utilizados nas maiores empresas do

Brasil

v. 10 n. 24 p. $74-102$ set./dez. 2010

BIANCO, Mônica de Fátima

Métodos e Práticas de Gestão e Organização do Trabalho na Empresa Brasileira de

Correios e Telégrafos

v. 10 n. 23 p. $59-79$ maio/ago. 2010

BRESSAN, Aureliano Angel

Alavancagem Financeira como Estratégia de Financiamento do Processo de Crescimento de Empresas Brasileiras de Capital Aberto no Período 1995-2002

v. 10 n. 23 p. 23-39 maio/ago. 2010

BRITTO, Eduardo de

O dono da bola - uma discussão sobre aspectos morais e éticos do comportamento individualista

v. 10 n. 24 p. $150-161$ set./dez. 2010 
CAMPOS, Luiz Claudio Marques

Provisão compartilhada de Serviços Públicos: configuração e desafios a partir da análise da Política Nacional de Combate ao HIV/Aids

v. 10 n. 23 p. $100-117$ maio/ago. 2010

CONCER, Ronald de Oliveira

Grau de desenvolvimento, ambiente macroeconômico e geografia: uma análise da posição brasileira em investimentos diretos

v. 10 n. 22 p. 45-66 jan./abril 2010

COSTA, Maykell Leite da

Análise dos canais de comercialização: o caso dos produtos agroindustrializados no mercado público

v. 10 n. 23 p. $08-22$ maio/ago. 2010

CRUZ, Cláudia Andressa

Gestão estratégica do conhecimento: um estudo comparativo em empresas incubadas v. 10 n. 22 p. $110-130$ jan./abril 2010

DOMINGUES, Maria José

A qualidade da administração das instituições de ensino superior: um estudo multicaso em instituições privadas que oferecem cursos de graduação em Administração em Joinville, SC v. 10 n. 22 p. 09-30 jan./abril 2010

DORR, Andréa Cristina

Análise dos canais de comercialização: o caso dos produtos agroindustrializados no mercado público

v. 10 n. 23 p. $08-22$ maio/ago. 2010

DUFLOTH, Simone Cristina

Gestão da Informação numa IES: estudo de caso aplicado à avaliação para autorização e reconhecimento de cursos de graduação

v. 10 n. 22 p. $67-87$ jan./abril 2010

FERREIRA, Afonso Henriques Borges

A alocação de recursos dos regimes próprios de previdência social tem sido eficiente?

v. 10 n. 24 p. $48-73$ set./dez. 2010

FORNAZIER, Armando

Tendências na produção de vinhos no Brasil e no Chile

v. 10 n. 22 p. $88-108$ jan./abril 2010

GIVISIEZ, Lucas José Villas Boas

A alocação de recursos dos regimes próprios de previdência social tem sido eficiente?

v. 10 n. 24 p. $48-73$ set./dez. 2010

GONÇALVES, Miguel 
Aspectos teóricos de política industrial à luz de princípios de política econômica v. 10 n. 22 p. 31-44 jan./abril 2010

GRUNOW, Aloisio

Métodos de preço de transferência interna utilizados nas maiores empresas do

Brasil

v. 10 n. 24 p. $74-102$ set./dez. 2010

GUIMARÃES, Liliane de Oliveira

TAP Portugal: o Desafio de Ser Fênix

v. 10 n. 23 p. $118-134$ maio/ago. 2010

HEIN, Nelson

Métodos de preço de transferência interna utilizados nas maiores empresas do

Brasil

v. 10 n. 24 p. $74-102$ set./dez. 2010

JESUS, Marcos Ferreira

Efeitos da participação de mulheres em redes sociais: um estudo em um conselho de mulheres executivas

v. 10 n. 24 p. $09-27$ set./dez. 2010

JÚNIOR, Reginaldo Pinto Nogueira

A alocação de recursos dos regimes próprios de previdência social tem sido eficiente?

v. 10 n. 24 p. $48-73$ set./dez. 2010

JUNQUEIRA, Luis Renato

Alavancagem Financeira como Estratégia de Financiamento do Processo de Crescimento de Empresas Brasileiras de Capital Aberto no Período 1995-2002

v. 10 n. 23 p. 23-39 maio/ago. 2010

MACHADO, Hilka Vier

Efeitos da participação de mulheres em redes sociais: um estudo em um conselho de mulheres executivas

v. 10 n. 24 p. $09-27$ set./dez. 2010

MACIEL, Leandro Santos

Valor em risco de longo prazo: uma abordagem para modelos da Família Ach e redes neuronais

v. 10 n. 24 p. $74-102$ set./dez. 2010

MAINARDES, Emerson Wagner

A qualidade da administração das instituições de ensino superior: um estudo multicaso em instituições privadas que oferecem cursos de graduação em Administração em Joinville, SC v. 10 n. 22 p. 09-30 jan./abril 2010 
MELO, Pedro Antônio de

O Estado da arte em estratégia na Revista de Administração Contemporânea: um estudo bibliométrico

v. 10 n. 24 p. $28-47$ set./dez. 2010

MENDONÇA, Patrícia

Provisão compartilhada de Serviços Públicos: configuração e desafios a partir da análise da Política Nacional de Combate ao HIV/Aids

v. 10 n. 23 p. $100-117$ maio/ago. 2010

MONTEIRO, Érika Roberta

Grau de desenvolvimento, ambiente macroeconômico e geografia: uma análise da posição brasileira em investimentos diretos

v. 10 n. 22 p. $45-66$ jan./abril 2010

MOURA, Sheila Rodrigues

Práticas políticas em relações empresariais de terceirização: um estudo de caso v. 10 n. 24 p. $127-149$ set./dez. 2010

NAGANO, Marcelo Seido

Gestão estratégica do conhecimento: um estudo comparativo em empresas incubadas v. 10 n. 22 p. $110-130$ jan./abril 2010

NUNES, Marilene Gonçalves

Gestão da Informação numa IES: estudo de caso aplicado à avaliação para autorização e reconhecimento de cursos de graduação

v. 10 n. 22 p. $67-87$ jan./abril 2010

PEREIRA, Maurício Fernandes

O Estado da arte em estratégia na Revista de Administração Contemporânea: um estudo bibliométrico

v. 10 n. 24 p. $28-47$ set./dez. 2010

REYS, Marcos Alves dos

Análise dos canais de comercialização: o caso dos produtos agroindustrializados no mercado público

v. 10 n. 23 p. $08-22$ maio/ago. 2010

ROCZANSKI, Carla Regina Magagnin

O Estado da arte em estratégia na Revista de Administração Contemporânea: um estudo bibliométrico

v. 10 n. 24 p. $28-47$ set./dez. 2010

SÁNCHEZ, Gabriel Antonio Cartes

Tendências na produção de vinhos no Brasil e no Chile v. 10 n. 22 p. $88-108$ jan./abril 2010 
SARAIVA, Luiz Alex Silva

Práticas políticas em relações empresariais de terceirização: um estudo de caso

v. 10 n. 24 p. $127-149$ set./dez. 2010

SCHARF, Edson Roberto

O patrocínio do futebol como ferramenta do marketing esportivo para a construção de brand awareness

v. 10 n. 23 p. $80-99$ maio/ago. 2010

SILVA, Tania Nunes da

Tendências na produção de vinhos no Brasil e no Chile

v. 10 n. 22 p. $88-108$ jan./abril 2010

TANURE, Betânia

TAP Portugal: o Desafio de Ser Fênix

v. 10 n. 23 p. $118-134$ maio/ago. 2010

TEIXEIRA, Tadeu Gomes

Métodos e Práticas de Gestão e Organização do Trabalho na Empresa Brasileira de Correios e Telégrafos

v. 10 n. 23 p. $59-79$ maio/ago. 2010

TROCCOLI, Irene Raguenet

A importância da gestão profissional em uma Empresa Familiar - Joalharia Meridiano Ltda

v. 10 n. 23 p. $40-58$ maio/ago. 2010

TOSTA, Kelly Cristina Benetti Tonani

O Estado da arte em estratégia na Revista de Administração Contemporânea: um estudo bibliométrico

v. 10 n. 24 p. $28-47$ set./dez. 2010

TUROLLA, Frederico Araujo

Grau de desenvolvimento, ambiente macroeconômico e geografia: uma análise da posição brasileira em investimentos diretos

v. 10 n. 22 p. $45-66$ jan./abril 2010

VASCONCELOS, Maria Celeste Reis Lobo de

Gestão da Informação numa IES: estudo de caso aplicado à avaliação para autorização e reconhecimento de cursos de graduação

v. 10 n. 22 p. $67-87$ jan./abril 2010 